\title{
RENDIMIENTO DIAGNÓSTICO DE LA CITOLOGÍA DE LAVADO BRONQUIAL EN EL ULTRASONIDO ENDOBRONQUIAL-EBUS LINEAL
}

\author{
${ }^{3}$ Álvarez S, 1,2 Giraldo-Cadavid LF, ${ }^{3}$ Batanero A, ${ }^{3}$ Alfayate J, ${ }^{3}$ Martínez-Muñiz FB, ${ }^{3}$ Soto FJ, ${ }^{3}$ Flandes J \\ ${ }^{1}$ Fundación Neumológica Colombiana, ${ }^{2}$ Universidad de La Sabana. Bogotá, Colombia. \\ ${ }^{3}$ Hospital Fundación Jiménez-Díaz. Madrid, España
}

\section{INTRODUCCIÓN Y OBJETIVO}

El ultrasonido endobronquial (EBUS) es un procedimiento con alto rendimiento diagnóstico para el diagnóstico y estadificación de los tumores mediastinales. Durante el procedimiento es frecuente que, además de las muestras recogidas por punción aspiración con aguja fina (PAAF), se envien muestras del lavado bronquial para citología, pero se desconoce la utilidad de esto último. Nuestro objetivo fue evaluar la validez del lavado bronquial en EBUS.

\section{MATERIALES Y MÉTODOS}

Para evaluar el rendimiento y exactitud diagnósticas de la citología del lavado bronquial como complemento de la PAAF guiada por EBUS del mediastino se realizó un estudio de corte transversal entre junio de 2016 y enero de 2017 incluyendo todos los EBUS realizados a través de la tráquea. El patrón de referencia fue el estudio histopatológico de la PAAF del EBUS.

\section{RESULTADOS}

Se analizaron un total de 165 EBUS, $62 \%$ de los pacientes fueron hombres y su edad promedio fue 63,7 años. Las estaciones ganglionares puncionadas con mayor frecuencia fueron la $7(52 \%)$ y la $4 \mathrm{R}(34 \%)$, el $9 \%$ fueron de masas mediastínicas. La EBUS fue diagnóstica en el $90 \%$ de los casos, pero la citología del lavado bronquial fue diagnóstica en sólo el $2 \%$ de los casos y en ninguno de estos casos mostró un diagnóstico diferente al de la PAAF.

La sensibilidad de la citología del lavado bronquial fue del 2,8\% (IC95\%: 0,8-6,9), la especificidad del $100 \%$ (IC95\%: 83,2-100), el área bajo la curva ROC fue de 0,51 (IC95\%: 0,37-0,66; P=0.86), su exactitud diagnóstica global fue de 0,15 (IC95\%: 0,10-0,21) y el Odds-Ratio diagnóstico de 1,3 (IC95\%: 0,07-26,3; P=0,57).

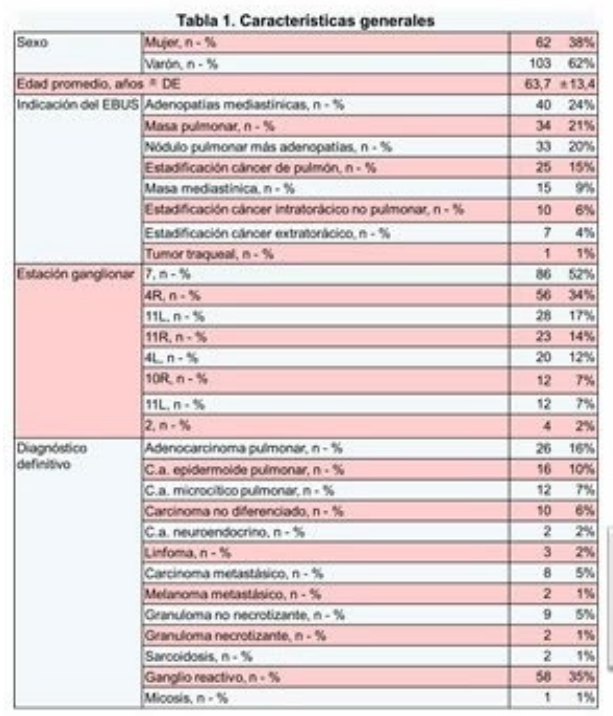

\begin{tabular}{|c|c|c|c|}
\hline \multirow[b]{2}{*}{$\begin{array}{c}\text { Citología del lavado } \\
\text { bronquial }\end{array}$} & \multicolumn{2}{|c|}{ PAAF (EBUS) } & \multirow[b]{2}{*}{ Total } \\
\hline & + & - & \\
\hline+ & 4 & 0 & 4 \\
\hline - & 141 & 20 & 161 \\
\hline Total & 145 & 20 & 165 \\
\hline
\end{tabular}

\begin{tabular}{|c|c|c|}
\hline \multicolumn{2}{|c|}{ Estadistico } & \multirow{2}{*}{$\begin{array}{c}\text { IC } 95 \% \\
0,10-0,21\end{array}$} \\
\hline Exactitud global & 0,15 & \\
\hline AUC-ROC & 0,51 & $0,37-0,66$ \\
\hline Sensibilidad & $2,8 \%$ & $0,8 \cdot 6,9$ \\
\hline Especificidad & $100 \%$ & $83,2-100,0$ \\
\hline+ +LR & 1,30 & $0,07-23,19$ \\
\hline -LR & 0,99 & $0,92-1,07$ \\
\hline$+P V$ & $100 \%$ & $47,3-100$ \\
\hline -PV & $12,4 \%$ & $8,0-18,2$ \\
\hline
\end{tabular}

\section{CONCLUSIONES}

La citologia del lavado bronquial realizada durante la EBUS tiene escasa utilidad diagnóstica y no aporta información adicional a la obtenida por la PAAF. 